\title{
Mortality from suicide among agricultural, fishery, forestry and hunting workers in Italy and the contribution of work-related factors
}

\author{
Gianfranco Alicandro (ㄷ) , Enrico Grande, 'Gabriella Sebastiani, \\ Francesco Saverio Violante, ${ }^{2}$ Carlo La Vecchia, ${ }^{3}$ Luisa Frova ${ }^{1}$
}

- Additional material is published online only. To view please visit the journal online (http://dx.doi.org/10.1136/) oemed-2020-106743).

'Directorate for Social Statistics and Welfare, Integrated System for Health, Social Assistance and Welfare, National Institute of Statistics (ISTAT), Rome, Italy ${ }^{2}$ Occupational Health Unit, Department of Medical and Surgical Sciences, Università di Bologna, Bologna, Italy Department of Clinical Sciences and Community Health, Università degli Studi di Milano, Milan, Italy

Correspondence to Dr Gianfranco Alicandro, National institute of Statistics (ISTAT), Rome 00198, Italy; gianfranco.alicandro@istat.it

Received 27 May 2020 Revised 5 August 2020 Accepted 26 August 2020 Published Online First

1 October 2020

\section{ABSTRACT}

Objectives Excess risk of suicide has been reported among workers in agriculture, fishery, forestry and hunting (AFFH). However, there is still uncertainty in the quantification of the risk and in the contribution of work-related factors. We aimed to quantify the suicide mortality risk among these workers in Italy.

Methods We carried out a historical cohort study based on record linkage between the 2011 Italian census and the mortality archives for years 2012-2017. The mortality rate ratio (MRR) was used as a measure of risk. MRR was estimated through quasi-Poisson regression models using workers in other sectors as reference category. Models were adjusted for age, citizenship, marital status, area of residence, education, employment status and hours worked per week.

Results The cohort included 1004655 workers employed in the AFFH sector and 15269181 workers in other sectors. During the 6-year follow-up, 559 deaths from suicide (500 men and 59 women) occurred among AFFH workers and 5917 (4935 men and 982 women) among workers in other sectors. The MRR for suicide was $1.36(95 \% \mathrm{Cl} 1.19$ to 1.55$)$ among men and 1.18 (95\% Cl 0.87 to 1.60) among women. The excess risk was remarkably high for casual and fixed-term contract workers (3.01, 95\% Cl 1.50 to 6.04).

Conclusions Male workers in AFFH are at high risk of suicide mortality, and casual and fixed-term contract workers are at exceedingly high risk. Our study also suggests a higher risk among single, highly educated and long-hours workers. Female workers in AFFH do not have an appreciably increased risk.

\section{INTRODUCTION}

Working in agriculture, fishery, forestry and hunting (AFFH) has been associated with increased risk of suicide mortality. ${ }^{1-7}$

Several factors related to the work environment may be responsible for such an increased risk, including social isolation, climate variability, financial difficulties, overwork, and easy access to firearms, pesticides and other chemical substances. ${ }^{6-15}$ A high prevalence of mental health problems, including anxiety and depression symptoms, and poor access to mental health services have also been implicated in the increased risk of suicide among AFFH workers. ${ }^{16}$ Exposure to pesticides, mainly organophosphates, has also been

\section{Key messages}

What is already known about this subject?

- Several work-related conditions, including social isolation, climate variability, financial difficulties, overwork as well as easy access to firearms and pesticides, have been implicated in the increased risk of suicide among workers in agriculture, fishery, forestry and hunting.

What are the new findings?

- We found an excess suicide mortality of $36 \%$ in men, and a higher excess among long-hours workers and casual and fixed-term contract workers.

- The excess was modest (18\%) and nonsignificant in women.

How might this impact on policy or clinical practice in the foreseeable future?

- A more effective surveillance of the working conditions, with particular attention to screening for work-related stress, social isolation and mental health problems, is needed to reduce the excess risk.

linked to poor mental health among farmers, but this is still debated. ${ }^{17}$

A systematic review and meta-analysis of 32 studies reported a pooled excess risk of suicide among AFFH workers of $1.48 .^{18}$ However, the review found substantial heterogeneity according to study design, measure of effect size and the reference group used for comparisons. Indeed, no excess risk was found in cohort studies and in studies using the standardized mortality ratio as a measure of risk, and a greater excess in studies using one specific occupation group as reference (generally high-skilled occupations) as compared with the general population or all other occupational groups. Moreover, the authors were unable to show the results according to employment status, since the original studies did not report disaggregated estimates. This last aspect is of major importance, since it would allow a better characterisation of the risk and would provide important insights into the work-related factors underlying the excess risk of suicide in this working population. 
We aimed to quantify the excess risk of suicide among AFFH workers using a census-based nationwide cohort in Italy, and to verify differences across strata of sociodemographic variables and selected work-related factors, namely overtime work and employment status.

\section{METHODS}

\section{Study design}

We carried out a historical cohort study based on record linkage between the 2011 Italian census and the mortality archives for the calendar years 2012-2017. The cohort included all residents registered in the 2011 Population and Housing Census and who were alive on 1 January 2012 and did not emigrate over the period elapsed between the census reference date (9 October 2011) and 1 January 2012 (the start of follow-up).

The 2011 census collected main demographic and socioeconomic characteristics of the Italian population. To this purpose, two questionnaires were used: a short form, including a limited number of questions required by the European Union regulations, and a long form, including a larger set of questions and among them the sector of economic activity. The long form was sent to all households living in municipalities with less than 20000 residents and to a random sample (one-third of the households) of individuals living in municipalities with 20000 residents or more and in all provincial capitals.

Until 2011 census took place every 10 years and participation was mandatory. Questionnaires were mailed out to all the households included in municipal registers and respondents had the option of returning them back online, by mail or by delivery to municipal collection offices. The coverage of the census was high, with an undercoverage rate of $1.07 \%$ estimated by the Post Enumeration Survey. ${ }^{19}$

Follow-up data included vital status, cause of death and migration.

From the mortality archives we retrieved the date of death and the underlying cause of death coded according to the International Classification of Diseases (ICD), 10th Revision. From the population registers, we obtained all individuals who left the country.

Records in the mortality archives and those in the population registers were linked to the individuals registered in the census using the fiscal code, a composite alphanumeric code made up of 16 digits, as linkage key. It is derived from the first name, surname, sex, and date and place of birth of the individual.

The cohort was conceived within the project 'IF IST-2646 Analisi delle differenze socio-economiche nella mortalità', which was included in the National Statistical Program and approved by the Italian Data Protection Authority. Further details on the cohort profile and the project are given elsewhere. ${ }^{19}$

\section{Study population}

We selected all employed individuals aged between 20 and 64 years at the start of follow-up and with available data on economic sector. We considered only individuals aged 20 years and over because younger individuals may have not completed high school, and we wanted to include education in our analysis since it was previously found an important predictor of premature mortality in this cohort. ${ }^{20}$ Study population were grouped according to the sector of economic activity as follows: (1) AFFH workers and (2) workers in other sectors. Individuals were followed up for 6 years from 1 January 2012 until 31 December 2017.

\section{Exposure and outcome}

Working in AFFH was the exposure of this study and mortality from suicide was the outcome. Deaths for which the underlying cause of death was suicide were identified using ICD-10 codes $\mathrm{X} 60-\mathrm{X} 84$ and Y87.0.

\section{Collected variables}

We also retrieved a set of other socioeconomic and workrelated variables, including sex, age, citizenship, geographical area of residence, attained education, employment status and number of hours usually worked per week. Age was categorised into 5-year age groups in the regression model and in 10-year age groups in the stratified analysis. Citizenship was coded as 'Italian' and 'foreign'. We grouped the municipality of residence in five major areas (North-West, North-East, Centre, South and Sicily and Sardinia). Sardinia was considered separately due to the recognised excess risk of suicide in this region. ${ }^{21}$ Education was categorised into two groups: middle school or less and high school or university. Employment status included the following categories: casual workers, fixed-term contract workers (which included seasonal workers), entrepreneurs, professionals, selfemployees, family adjuvants and cooperative members. Given the small number of individuals in some categories of the census original variable, casual and fixed-term contract workers, entrepreneurs and professionals, family adjuvant and cooperative members were grouped. Long working hours was defined as working 55 hours or more per week. ${ }^{22}$

\section{Statistical analysis}

Categorical variables were compared between groups using the $\chi^{2}$ test, while continuous variables were compared through t-test. Years in follow-up were computed from the start of follow-up until death, migration or end of the study period, whichever came first. Mortality rates were expressed as number of deaths per 100000 person-years.

To provide an absolute measure of risk, we estimated the cumulative probability of suicide death as a function of time using the Aalen-Johansen estimator and considering non-suicide deaths as a competing event. ${ }^{23}$ Cumulative probability functions were compared between AFFH workers and other workers using the Gray's test. ${ }^{24}$ To verify if working in the AFFH sector increased suicide and non-suicide mortality rates, we estimated the cause-specific mortality rate ratio (MRR) by quasi-Poisson regression models. Two models were used: a partly adjusted model including terms for occupation category and age-at-risk, and a fully adjusted model including also terms for citizenship, geographical area of residence, education, employment status and number of hours usually worked per week.

We also carried a subgroup analysis by estimating the MRR of suicide in the strata of selected socioeconomic and work-related characteristics, including age, citizenship, geographical area of residence, education, employment status and number of hours usually worked per week. The heterogeneity across the strata of each socioeconomic and work-related characteristic was evaluated by adding an interaction term between the occupation category and the socioeconomic characteristics in the regression models. A drop-in-deviance test was used to test the significance of the interaction term after adjusting for overdispersion. The test statistic was divided by the estimated dispersion parameter and compared with the $F$ distribution, with the difference in the model $\mathrm{df}$ in the numerator and the $\mathrm{df}$ for the larger model in the denominator. Due to the limited number of suicide deaths among women, we performed the subgroup analysis only among 
Table 1 Sociodemographic characteristics of the cohorts of workers aged 20-64 years on 1 January 2012 (enrolment date) by sex and sector of economic activity.

\begin{tabular}{|c|c|c|c|c|c|c|}
\hline & \multicolumn{2}{|l|}{ Men } & \multicolumn{2}{|l|}{ Women } & \multicolumn{2}{|l|}{ Both sexes } \\
\hline & AFFH workers & $\begin{array}{l}\text { Workers in other } \\
\text { sectors }\end{array}$ & AFFH workers & $\begin{array}{l}\text { Workers in other } \\
\text { sectors }\end{array}$ & AFFH workers & $\begin{array}{l}\text { Workers in other } \\
\text { sectors }\end{array}$ \\
\hline Number of workers & 642309 & 8855215 & 362346 & 6413966 & 1004655 & 15269181 \\
\hline \multicolumn{7}{|l|}{ Age groups at enrolment (years) } \\
\hline $20-29$ & 14.2 & 14.3 & 10.4 & 15.0 & 12.8 & 14.6 \\
\hline $30-39$ & 23.2 & 27.4 & 22.9 & 29.1 & 23.1 & 28.1 \\
\hline $40-49$ & 30.4 & 31.5 & 33.7 & 31.8 & 31.5 & 31.6 \\
\hline $50-59$ & 25.2 & 22.5 & 28.5 & 21.3 & 26.4 & 22.0 \\
\hline $60-64$ & 7.0 & 4.3 & 4.6 & 2.8 & 6.2 & 3.7 \\
\hline \multicolumn{7}{|l|}{ Marital status } \\
\hline Single & 32.7 & 34.8 & 19.7 & 32.9 & 28.0 & 34.0 \\
\hline Married & 61.5 & 57.9 & 70.4 & 54.4 & 64.7 & 56.4 \\
\hline Separated/divorced/widowed & 5.8 & 7.4 & 10.0 & 12.8 & 7.3 & 9.6 \\
\hline \multicolumn{7}{|l|}{ Area of residence } \\
\hline North-West & 17.2 & 29.7 & 12.7 & 31.9 & 15.6 & 30.7 \\
\hline North-East & 20.8 & 23.2 & 19.8 & 25.3 & 20.4 & 24.1 \\
\hline Centre & 13.3 & 18.7 & 12.3 & 19.9 & 13.0 & 19.2 \\
\hline South and Sicily & 44.0 & 25.7 & 53.0 & 20.3 & 47.3 & 23.4 \\
\hline Sardinia & 4.7 & 2.6 & 2.2 & 2.6 & 3.8 & 2.6 \\
\hline \multicolumn{7}{|l|}{ Citizenship } \\
\hline Italian & 86.5 & 92.3 & 90.1 & 91.2 & 87.8 & 91.8 \\
\hline Foreign & 13.5 & 7.7 & 9.9 & 8.8 & 12.2 & 8.2 \\
\hline \multicolumn{7}{|l|}{ Employment status } \\
\hline Employees & 60.1 & 72.3 & 67.6 & 80.2 & 62.8 & 75.6 \\
\hline Casual and fixed-term contract workers & 3.2 & 2.4 & 4.1 & 4.0 & 3.5 & 3.0 \\
\hline Entrepreneurs/professionals & 7.6 & 10.0 & 3.7 & 5.8 & 6.2 & 8.2 \\
\hline Self-employed/family adjuvants & 27.5 & 14.7 & 24.0 & 9.3 & 26.2 & 12.4 \\
\hline Cooperative members & 1.6 & 0.6 & 0.6 & 0.8 & 1.2 & 0.7 \\
\hline \multicolumn{7}{|l|}{ Level of education } \\
\hline Middle school or less & 65.5 & 42.2 & 66.2 & 29.2 & 65.8 & 36.8 \\
\hline High school, university & 34.5 & 57.8 & 33.8 & 70.8 & 34.2 & 63.2 \\
\hline \multicolumn{7}{|l|}{$\begin{array}{l}\text { Long working hours ( } \geq 55 \text { hours/ } \\
\text { week) }\end{array}$} \\
\hline No & 90.2 & 95.4 & 95.8 & 98.3 & 92.2 & 96.6 \\
\hline Yes & 9.8 & 4.6 & 4.2 & 1.7 & 7.8 & 3.4 \\
\hline
\end{tabular}

Data are column percentages unless otherwise specified. The $\chi^{2}$ test for comparison between groups of workers indicated a significant difference in the distribution of all sociodemographic variables $(\mathrm{p}<0.001)$.

$\mathrm{AFFH}$, agriculture, fishery, forestry and hunting.

men. We also split the observation period into 2-year intervals and estimated the MRR for each interval to evaluate if the risk among AFFH workers changed over the period.

The distribution of methods of suicide was compared between AFFH workers and workers in other sectors using the $\chi^{2}$ test.

As a sensitivity analysis, we estimated the MRR among AFFH workers using a different reference category, namely 'manual workers in other sectors', who had comparable levels of education $(65.8 \%$ of AFFH workers and $64.8 \%$ of manual workers in other sectors had less than high school education). All statistical tests were performed with a significance level of $\alpha=0.05$.

\section{RESULTS}

The cohort included 1004655 workers employed in AFFH (642309 men and 362346 women) and 15269181 workers in other sectors (8855215 men and 6413966 women).

Table 1 shows the baseline demographic and socioeconomic characteristics of the two groups of workers. Workers in AFFH were older than those working in other sectors (mean age (SD) was 43.4 (10.9) vs $41.7(10.5), \mathrm{p}<0.001$, respectively). They were more likely to be foreign, married, less educated and living in Southern Italy. A higher percentage were self-employed and family adjuvants, whereas the percentage of employees was lower as compared with workers in other sectors. A higher frequency of AFFH workers reported working 55 hours or more per week as compared with workers in other sectors.

During the 6-year follow-up, 559 deaths from suicide (500 men and 59 women) occurred among AFFH workers and 5917 (4935 men and 982 women) among workers in other sectors. Figure 1 shows the cumulative probability function for suicide and non-suicide death among AFFH and other workers by sex. In men, the cumulative probabilities of suicide death (per 100 000 workers) over the 6-year follow-up were 78.1 (95\% CI 71.6 to 85.3 ) among AFFH workers and 56.0 (95\% CI 54.4 to 57.6) among other workers ( $\mathrm{p}<0.001)$, while the cumulative probabilities of non-suicide death were 1380 (95\% CI 1351 to 1409) among AFFH workers and 1026 (95\% CI 1018 to 1033) among other workers $(\mathrm{p}<0.001)$. In women, the cumulative 

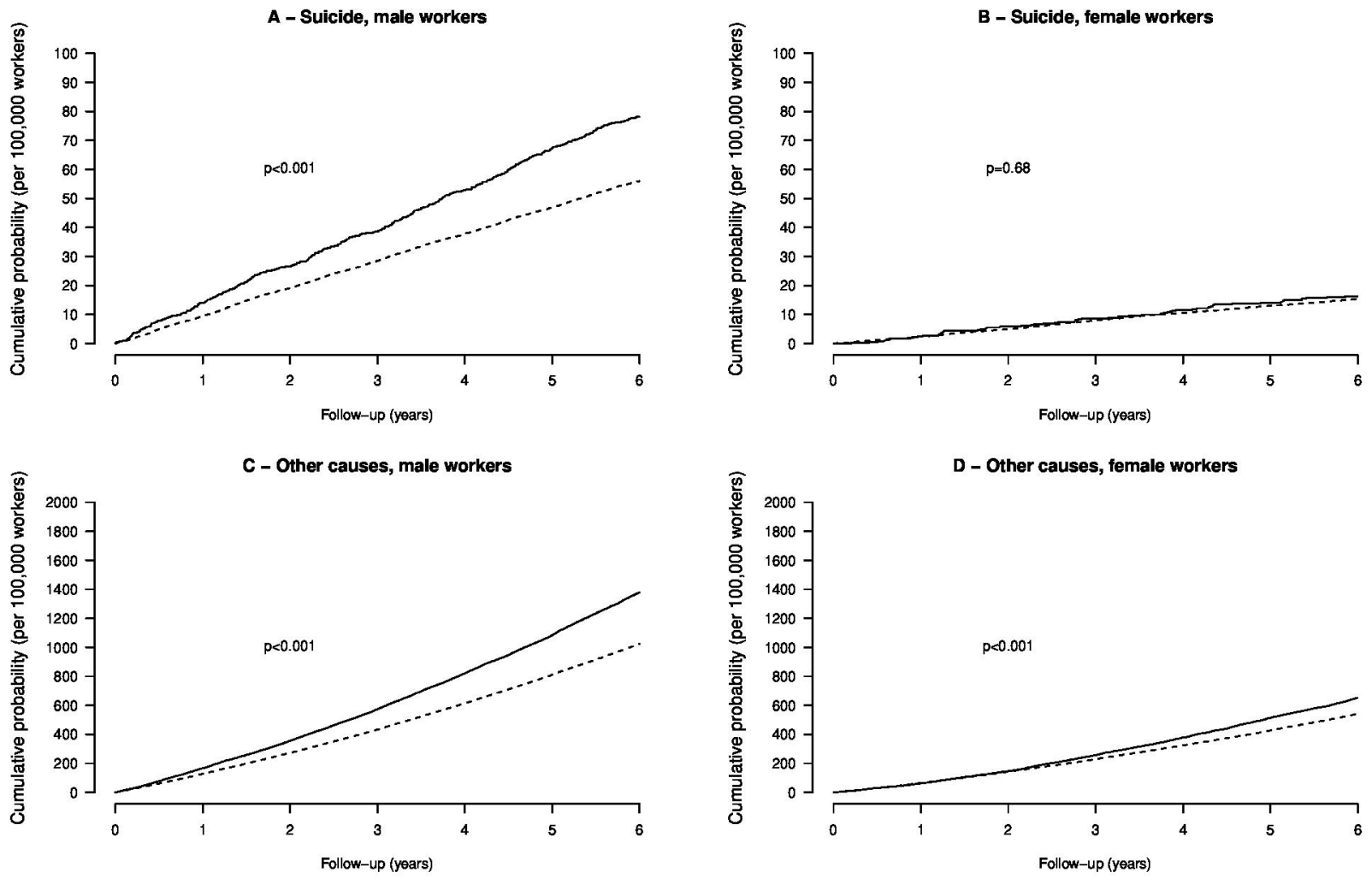

- AFFH workers

-.- Workers in other sectors

Figure 1 Cumulative probability functions (per 100000 workers) of suicide (panel A: male workers, panel B: female workers) and non-suicide death (panel C: male workers, panel D: female workers) by sector of economic activity among workers aged 20-64, with follow-up from 2012 to 2017 . AFFH, agriculture, fishery, forestry and hunting.

probabilities of suicide death were 16.3 (95\% CI 12.6 to 21.1 ) among AFFH workers and 15.4 (95\% CI 14.4 to 16.4 ) among other workers $(p=0.65)$, while the cumulative probabilities of non-suicide death were 652 (95\% CI 626 to 679) among AFFH workers and 541 (95\% CI 535 to 547) among other workers $(\mathrm{p}<0.001)$.
Table 2 shows the number of suicide and non-suicide deaths as well as the corresponding MRR among AFFH workers. The MRR of suicide obtained from the fully adjusted model was 1.36 (95\% CI 1.19 to 1.55$)$ in men and 1.18 (95\% CI 0.87 to 1.60$)$ in women. Men also had a slight excess mortality from other causes, while no significant differences were observed among women.

Table 2 Number of suicide and non-suicide deaths, mortality rates and cause-specific MRR by sex among AFFH workers aged 20-64, with followup from 2012 to 2017

\begin{tabular}{|c|c|c|c|c|c|c|}
\hline & \multicolumn{2}{|l|}{ Deaths (n) } & \multicolumn{2}{|c|}{$\begin{array}{l}\text { Mortality rates } \\
\text { (per } 100000 \text { person-years) }\end{array}$} & \multirow{2}{*}{$\begin{array}{l}\text { MRR from partly } \\
\text { adjusted model } \\
(95 \% \mathrm{Cl})^{*}\end{array}$} & \multirow{2}{*}{$\begin{array}{l}\text { MRR from fully } \\
\text { adjusted model } \\
(95 \% \mathrm{Cl}) \dagger\end{array}$} \\
\hline & AFFH workers & $\begin{array}{l}\text { Workers in other } \\
\text { sectors }\end{array}$ & AFFH workers & $\begin{array}{l}\text { Workers in other } \\
\text { sectors }\end{array}$ & & \\
\hline \multicolumn{7}{|c|}{ Suicide mortality } \\
\hline Both sexes & 559 & 5917 & 9.35 & 6.51 & $1.32(1.20$ to 1.46$)$ & $1.33(1.19$ to 1.50$)$ \\
\hline Men & 500 & 4935 & 13.11 & 9.38 & 1.37 (1.22 to 1.54$)$ & $1.36(1.19$ to 1.55$)$ \\
\hline Women & 59 & 982 & 2.73 & 2.57 & $1.01(0.76$ to 1.35$)$ & 1.18 (0.87 to 1.60$)$ \\
\hline \multicolumn{7}{|c|}{ Mortality from other causes } \\
\hline Both sexes & 11186 & 124975 & 187.1 & 137.5 & $1.11(1.09$ to 1.14$)$ & 1.04 (1.01 to 1.06$)$ \\
\hline Men & 8828 & 90380 & 231.4 & 171.7 & 1.16 (1.13 to 1.19$)$ & $1.06(1.03$ to 1.09$)$ \\
\hline Women & 2358 & 34595 & 109.0 & 90.4 & $0.98(0.92$ to 1.03$)$ & $0.95(0.89$ to 1.02$)$ \\
\hline
\end{tabular}

Reference category: workers in other sectors.

${ }^{*}$ The partly adjusted model included terms for sector of economic activity (AFFH, other sectors), age-at-risk (5-year age groups with the last group 65 and over) and sex (only for the model including both men and women).

tThe fully adjusted model included further terms for marital status (single, married, separated, divorced or widowed), citizenship (Italian, foreign), geographical area of residence (North-West, North-East, Centre, Sardinia, South and Sicily), level of education (high school or university, middle school or less), employment status (casual and fixed-term contract workers, cooperative members, employees, entrepreneurs/professionals, self-employed/family adjuvants) and long working hours ( $\leq 55$ or $>55$ hours worked per week). AFFH, agriculture, fishery, forestry and hunting; $\mathrm{Cl}$, Confidence Interval; MRR, mortality rate ratio. 
Table 3 Number of suicide and non-suicide deaths, mortality rates and cause-specific MRR by selected sociodemographic characteristics among male AFFH workers aged 20-64 p, with follow-up from 2012 to 2017

\begin{tabular}{|c|c|c|c|c|c|}
\hline \multirow[b]{2}{*}{ Sociodemographic or work-related characteristics } & \multicolumn{2}{|l|}{ Deaths (n) } & \multicolumn{2}{|c|}{$\begin{array}{l}\text { Rates } \\
\text { (per } 100000 \text { person-years) }\end{array}$} & \multirow[b]{2}{*}{$\operatorname{MRR}(95 \% \mathrm{Cl})^{*}$} \\
\hline & AFFH workers & Workers in other sectors & AFFH workers & Workers in other sectors & \\
\hline \multicolumn{6}{|l|}{ Age groups } \\
\hline $20-29$ & 28 & 282 & 8.03 & 6.12 & 1.31 (0.86 to 1.99$)$ \\
\hline $30-39$ & 82 & 897 & 10.51 & 7.17 & $1.47(1.11$ to 1.95$)$ \\
\hline $40-49$ & 135 & 1579 & 12.19 & 9.5 & 1.28 (0.99 to 1.64$)$ \\
\hline $50-59$ & 174 & 1575 & 16.29 & 11.38 & $1.43(1.21$ to 1.60$)$ \\
\hline$\geq 60$ & 81 & 602 & 15.88 & 11.92 & 1.34 (1.01 to 1.78$)$ \\
\hline $\mathrm{p}$ valuet & & & & & 0.87 \\
\hline \multicolumn{6}{|l|}{ Marital status } \\
\hline Married & 241 & 2343 & 10.28 & 7.69 & 1.32 (1.14 to 1.53$)$ \\
\hline Separated/divorced/widowed & 42 & 673 & 18.97 & 17.4 & $1.08(0.73$ to 1.60$)$ \\
\hline Single & 217 & 1919 & 17.38 & 10.5 & 1.54 (1.35 to 1.76$)$ \\
\hline $\mathrm{p}$ valuet & & & & & 0.065 \\
\hline \multicolumn{6}{|l|}{ Citizenship } \\
\hline Foreign & 23 & 202 & 4.50 & 5.00 & 0.89 (0.39 to 2.05$)$ \\
\hline Italian & 477 & 4733 & 14.44 & 9.74 & 1.45 (1.30 to 1.61$)$ \\
\hline $\mathrm{p}$ valuet & & & & & 0.12 \\
\hline \multicolumn{6}{|l|}{ Area of residence } \\
\hline North-West & 61 & 849 & 11.99 & 8.61 & 1.50 (1.22 to 1.84$)$ \\
\hline North-East & 131 & 1397 & 16.55 & 11.44 & 1.41 (1.18 to 1.68$)$ \\
\hline Centre & 100 & 1565 & 15.23 & 10.01 & 1.38 (1.04 to 1.83$)$ \\
\hline Sardinia & 39 & 196 & 21.85 & 14.31 & 1.51 (1.09 to 2.09 ) \\
\hline South and Sicily & 169 & 928 & 10.06 & 6.85 & 1.44 (1.07 to 1.93 ) \\
\hline $\mathrm{p}$ valuet & & & & & 1.00 \\
\hline \multicolumn{6}{|l|}{ Level of education } \\
\hline High school, university & 158 & 2472 & 11.98 & 8.13 & 1.49 (1.18 to 1.89$)$ \\
\hline Middle school or less & 342 & 2463 & 13.7 & 11.09 & 1.22 (1.09 to 1.37$)$ \\
\hline $\mathrm{p}$ valuet & & & & & 0.10 \\
\hline \multicolumn{6}{|l|}{ Employment status } \\
\hline Casual and fixed-term contract workers & 32 & 98 & 25.94 & 7.88 & 3.01 (1.50 to 6.04$)$ \\
\hline Cooperative members & 7 & 32 & 11.82 & 9.57 & 1.03 (0.51 to 2.11$)$ \\
\hline Employees & 244 & 3408 & 10.64 & 8.96 & 1.18 (1.02 to 1.37$)$ \\
\hline Entrepreneurs/professionals & 38 & 513 & 13.04 & 9.77 & 1.31 (0.93 to 1.86$)$ \\
\hline Self-employed/family adjuvant & 179 & 884 & 17.08 & 11.39 & $1.46(1.25$ to 1.71$)$ \\
\hline $\mathrm{p}$ valuet & & & & & 0.005 \\
\hline \multicolumn{6}{|l|}{ Long working hours ( $\geq 55$ hours/week) } \\
\hline No & 429 & 4688 & 12.47 & 9.34 & 1.31 (1.15 to 1.50$)$ \\
\hline Yes & 71 & 247 & 18.95 & 10.24 & 1.81 (1.41 to 2.33$)$ \\
\hline $\mathrm{p}$ valuet & & & & & 0.069 \\
\hline \multicolumn{6}{|l|}{ Years in follow-up } \\
\hline $1-2$ & 171 & 1690 & 13.35 & 9.57 & 1.35 (1.07 to 1.72$)$ \\
\hline $3-4$ & 168 & 1652 & 13.20 & 9.41 & $1.38(1.18$ to 1.60$)$ \\
\hline $5-6$ & 161 & 1593 & 12.77 & 9.15 & 1.38 (1.14 to 1.66$)$ \\
\hline$p$ valuet & & & & & 1.00 \\
\hline \multicolumn{6}{|c|}{$\begin{array}{l}\text { Reference category: workers in other sectors. } \\
\text { *MRR and corresponding } 95 \% \mathrm{Cl} \text { were obtained from quasi-Poisson regression models including terms for age-at-risk (5-year age groups with the last group } 65 \text { and over) and } \\
\text { sector of economic activity (AFFH, other sectors). } \\
\text { tTest for a different MRR across the strata of sociodemographic or work-related characteristics. } \\
\text { AFFH, agriculture, fishery, forestry and hunting; MRR, mortality rate ratio. }\end{array}$} \\
\hline \multicolumn{6}{|c|}{ 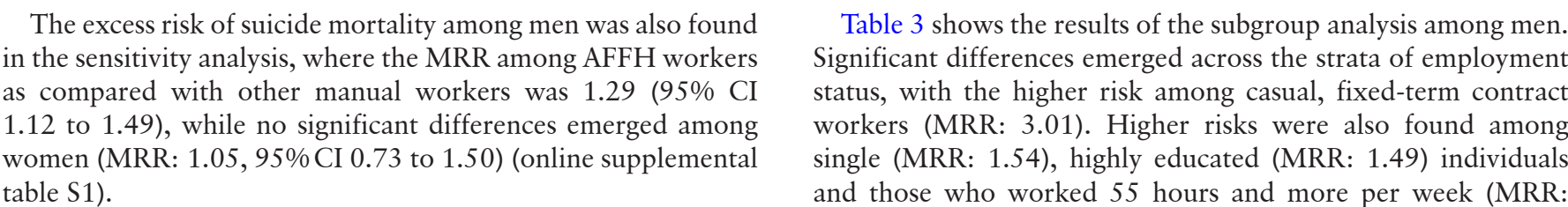 } \\
\hline
\end{tabular}




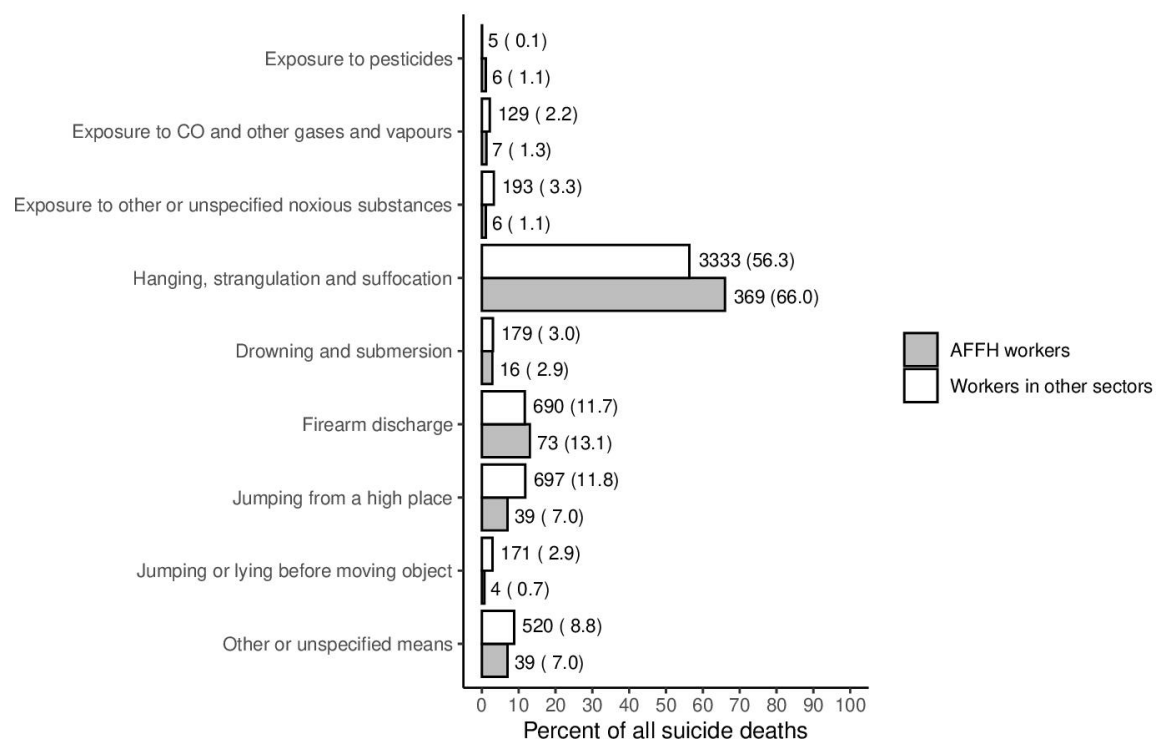

Figure 2 Number of suicide deaths (per cent of all suicide deaths) among AFFH workers and workers in other sectors by method of suicide among male and female workers aged 20-64, with follow-up from 2012 to 2017. AFFH, agriculture, fishery, forestry and hunting; CO, carbon monoxide.

1.81), although the heterogeneity tests were not significant. No excess risk was found among foreign citizens, and we did not observe any significant trend in the MRR over the study period. Online supplemental table S2 shows the corresponding analysis for non-suicide deaths. Significant differences emerged across the strata of marital status, area of residence and education, with higher risks among single (MRR: 1.23), highly educated (MRR: 1.13) individuals and those living in Sardinia (MRR: 1.26), whereas no heterogeneity emerged across the strata of age, citizenship, employment status and long hours worked.

Figure 2 shows the frequency distribution of the methods of suicide in both sexes. The distribution was different between the groups of workers $(p<0.001)$, with hanging, strangulation and suffocation being more frequent, and jumping from a high place less frequent, among AFFH workers than other workers. The most common method in both groups was hanging, strangulation and suffocation $(66.0 \%$ of all suicides among $\mathrm{AFFH}$ workers and $56.3 \%$ among workers in other sectors), followed by firearm (13.1\% among AFFH workers and 11.7\% among workers in other sectors). Only 6 out of the 559 deaths from suicide $(1.1 \%)$ were due to pesticide ingestion.

\section{DISCUSSION}

We found an excess mortality from suicide in men, but not in women, working in AFFH. In addition, in men, the excess was remarkably high among casual and fixed-term contract workers, and greater among single, highly educated and long-hours workers, whereas no excess was found among foreign citizens.

Our estimate of the excess mortality is consistent with the pooled estimate from the meta-analysis by Klingelschmidt et al. ${ }^{18}$ Differences across single studies are likely attributable to the working population considered in terms of sex, age and type of occupation within the sector, as well as to the reference group used for comparison and the socioeconomic and cultural aspects of the various countries.

In Italy 3.5\% of the working population are employed in the AFFH sector. They are more likely men (around 70\%) and older as compared with workers in other sectors. Most are employed in farms with sole proprietorship; the majority of farms are of small size with less than 10 workers and $61 \%$ do not have any salaried employees. ${ }^{25}$ Farming in Italy is predominantly a family business with low degree of informatisation and very vulnerable to political and market changes.

Farmers' income is lower as compared with other economic sectors and is highly volatile, with many farms depending on direct payments due to low profitability. ${ }^{27}$ In this context, small farms are more vulnerable as small changes in costs and market revenue can have a high impact on their revenue.

Casual and fixed-term workers had the highest suicide mortality among AFFH workers. This was not observed for non-suicide mortality, thus indicating the presence of specific mechanisms linking these workers to a high risk of suicide. Low employment protection, job insecurity and high exposure to consequences of financial difficulties characterise casual and fixed-term contract workers and may affect their risk of suicide. ${ }^{28}$ Financial stress combined with other known risk factors related to the work environment, such as relationship issues and lack of social support, could explain the higher risk of suicide mortality among casual and fixed-term contract workers in this sector. ${ }^{829}$

In our study, the excess suicide mortality among AFFH workers was higher in single than married men. Worse health outcomes were consistently reported among singles, especially among men, and have been attributed to less healthy lifestyle, social isolation, poor social support and network, as well as to a selection effect, with less healthy persons, including those with psychiatric disorders, more likely to remain single. ${ }^{30}$

Our study also suggests that highly educated AFFH workers have a higher risk than their less educated counterparts. An Italian study found a higher risk of dying from suicide as compared with natural causes among working-age men with a high level of education than those less educated. ${ }^{31}$ The authors hypothesised that the high expectations among highly educated people make them more vulnerable to any setbacks or failures. Among workers in AFFH, this aspect could be exacerbated by the high exposure to social isolation and work-related stress. Moreover, a study on dairy farm operators showed that high work demands and expectations coupled with low control and lack of social support can lead to a poor psychosocial work environment, with increased stress, poor mental health, depression and suicide. ${ }^{32}$ 
In our study, long working hours tended to increase the risk associated with the AFFH sector. This is in agreement with previous studies showing that overwork is a risk factor for suicide in this occupational group. ${ }^{1618} 33$ Long working hours and more generally work-related constraints are recognised risk factors for developing mental illness, typically depression, among AFFH workers. 5162934

In agreement with the study by Bossard et al, ${ }^{5}$ we did not find a significant excess risk among women working in AFFH. Women working in AFFH are more likely to live in rural areas, and living in rural areas was associated with reduced risk of suicide among women, but not among men. ${ }^{35} 36$ Moreover, women living in rural areas are less reluctant than men in seeking help. ${ }^{37}$ These factors may, at least partly, explain the sex difference in the association between working in AFFH and suicide mortality found in our study.

Hanging, strangulation and suffocation are the most common methods of suicide among AFFH workers, followed by firearms discharge. This is consistent with a study on a cohort of French farmers, ${ }^{5}$ where hanging was the most frequent method of suicide, accounting for $\sim 60 \%$ of all suicide deaths. The low percentage of suicide by firearms is likely the consequence of the restrictive legislation on firearm ownership, registration and storage in Italy. ${ }^{38}$ Suicide by poisoning (including pesticides) was rare, and it was in line with the low rates of deaths by poisoning (both suicide and accidental) in the general population in Italy. ${ }^{39}$

The study also has some limitations. Occupational and employment information was collected only at baseline and therefore we could not take into account changes during the study period. Some degree of misclassification is expected from death certificate data, as a proportion of suicides could be misclassified as 'accidental', 'unknown' or 'undetermined' cause of death. Furthermore, misclassification could have been higher in rural areas due to the stigma associated with suicide, thus resulting in a potential underestimation of suicide mortality among AFFH. ${ }^{40}$ Finally, the census included only the resident population, and therefore we could not evaluate the risk of suicide among irregular migrants as well as all irregular workers in the agricultural sectors.

The main strengths of the study are the national coverage of data and the availability of detailed demographic and socioeconomic information, including employment status. In addition, this study provides unique data of suicide mortality among AFFH workers in Italy.

In conclusion, male workers in $\mathrm{AFFH}$ are at high risk of suicide mortality, and long working hours, casual and fixed-term work, and high education may increase the risk. This calls for a more effective surveillance of the working conditions, with particular attention to screening for work-related stress, social isolation and mental health problems. Reducing cultural barriers and facilitating access to mental health services would probably also be useful to reduce the excess risk in this sector.

Acknowledgements The authors would like to thank Dr Stefano Marchetti (National Institute of Statistics, Rome, Italy), Dr Elena Demuru (National Institute of Health, Rome, Italy) and Dr Angelo Lorenti (Max Planck Institute for Demographic Research, Rostock, Germany) for technical support with the record linkage procedure.

Contributors GA, CLV and FSV designed the study. GA analysed the data and wrote the first draft of the manuscript. GA and LF have full access to the data. All authors participated in the interpretation of the results and approved the final version of the manuscript.

Funding The authors have not declared a specific grant for this research from any funding agency in the public, commercial or not-for-profit sectors.

Competing interests None declared.
Patient consent for publication Not required.

Provenance and peer review Not commissioned; externally peer reviewed.

Data availability statement No data are available. The ISTAT, which holds the database containing data on this cohort, is open to collaborations with national and international research institutions. Open access to data is not possible and access to data is limited to the authorised personnel of the ISTAT since the Italian independent authority of data privacy does not allow providing microdata of the project. Nevertheless, collaborations in specific projects with other research groups or institutes are possible upon collaboration agreement approval from the Presidential Committee of the ISTAT. Further request of information on the cohort and on collaborations can be addressed to the principal investigator (LF, ISTAT, frova@istat. it, +39 0646737382).

\section{ORCID iD}

Gianfranco Alicandro http://orcid.org/0000-0002-0430-2714

\section{REFERENCES}

1 Meltzer H, Griffiths C, Brock A, et al. Patterns of suicide by occupation in England and Wales: 2001-2005. Br J Psychiatry 2008;193:73-6.

2 Andersen $\mathrm{K}$, Hawgood J, Klieve $\mathrm{H}$, et al. Suicide in selected occupations in Queensland: evidence from the state suicide register. Aust N Z J Psychiatry 2010;44:243-9.

3 Milner A, Spittal MJ, Pirkis J, et al. Suicide by occupation: systematic review and metaanalysis. Br J Psychiatry 2013;203:409-16.

4 Wada K, Eguchi H, Prieto-Merino D, et al. Occupational differences in suicide mortality among Japanese men of working age. J Affect Disord 2016;190:316-21.

5 Bossard C, Santin G, Guseva Canu I. Suicide among farmers in France: occupational factors and recent trends. J Agromedicine 2016;21:310-5.

6 Lee $\mathrm{H}-\mathrm{E}$, Kim H-R, Chung YK, et al. Mortality rates by occupation in Korea: a nationwide, 13-year follow-up study. Occup Environ Med 2016;73:329-35.

7 Ringgenberg W, Peek-Asa C, Donham K, et al. Trends and characteristics of occupational suicide and homicide in farmers and agriculture workers, 1992-2010. J Rural Health 2018;34:246-53.

8 Perceval M, Ross V, Kõlves K, et al. Social factors and Australian farmer suicide: a qualitative study. BMC Public Health 2018;18:1367.

9 Berry HL, Hogan A, Owen J, et al. Climate change and farmers' mental health: risks and responses. Asia Pac J Public Health 2011;23:119S-32.

10 Austin EK, Handley T, Kiem AS, et al. Drought-related stress among farmers: findings from the Australian rural mental health study. Med J Aust 2018;209:159-65.

11 Meadows GN, Enticott JC, Inder B, et al. Better access to mental health care and the failure of the Medicare principle of universality. Med J Aust 2015;202:190-4

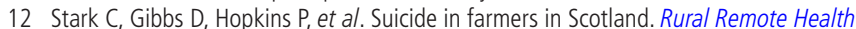
2006;6:509.

13 Weisskopf MG, Moisan F, Tzourio C, et al. Pesticide exposure and depression among agricultural workers in France. Am J Epidemiol 2013;178:1051-8.

14 Krawczyk N, Meyer A, Fonseca M, et al. Suicide mortality among agricultural workers in a region with intensive tobacco farming and use of pesticides in Brazil. J Occup Environ Med 2014;56:993-1000

15 Meyer A, Koifman S, Koifman RJ, et al. Mood disorders hospitalizations, suicide attempts, and suicide mortality among agricultural workers and residents in an area with intensive use of pesticides in Brazil. J Toxicol Environ Health A 2010;73:866-77.

16 Yazd SD, Wheeler SA, Zuo A. Key risk factors affecting farmers' mental health: A systematic review. Int J Environ Res Public Health 2019;16:4849.

17 Khan N, Kennedy A, Cotton J, et al. A PEST to mental health? exploring the link between exposure to Agrichemicals in farmers and mental health. Int J Environ Res Public Health 2019;16:1327

18 Klingelschmidt J, Milner A, Khireddine-Medouni I, et al. Suicide among agricultural, forestry, and fishery workers: a systematic literature review and meta-analysis. Scand $J$ Work Environ Health 2018:44:3-15.

19 Alicandro G, Grande E, Sebastiani G, et al. The 2011 Italian census cohort for the study of socioeconomic inequality in mortality. Int J Public Health 2020;65:693-7.

20 Alicandro G, Frova L, Sebastiani G, et al. Differences in education and premature mortality: a record linkage study of over 35 million Italians. Eur J Public Health 2018;28:231-7.

21 Masocco M, Pompili M, Vanacore $\mathrm{N}$, et al. Completed suicide and marital status according to the Italian region of origin. Psychiatr Q 2010;81:57-71.

22 Kivimäki M, Nyberg ST, Batty GD, et al. Long working hours as a risk factor for atria fibrillation: a multi-cohort study. Eur Heart J 2017;38:2621-8.

23 Kalbfeish P. The statistical analysis of failure time data. New Jersey: John Wiley \& Sons, Inc, Hoboken, 1980.

24 Gray RJ. A class of \$K\$-sample tests for comparing the cumulative incidence of a competing risk. Ann. Statist. 1988;16:1141-54.

25 Eurostat. Agriculture, forestry and fishing statistics, 2018. https://ec.europa.eu/ eurostat/documents/3217494/9455154/KS-FK-18-001-EN-N.pdf/a9ddd7db-c40c 48c9-8ed5-a8a90f4faa3f 
26 Istat. Struttura e caratteristiche delle unit economiche del settore agricolo. Statistiche report, 2017. Available: https://www.istat.it/it/files//2019/12/Struttura-unit economiche-settore-agricolo.pdf

27 European Commission. Developments of the income situation in the EU agricultural sector; 2010: 1-79. https://ec.europa.eu/agriculture/rica/pdf/hc0301_income.pdf [Accessed 27 May 2020].

28 Kim S-Y, Shin Y-C, Oh K-S, et al. Association between work stress and risk of suicidal ideation: a cohort study among Korean employees examining gender and age differences. Scand J Work Environ Health 2020;46:198-208.

29 Malmberg A, Simkin S, Hawton K. Suicide in farmers: editorial. Br J Psychiatry 1999:175:103-5.

30 Robards J, Evandrou M, Falkingham J, et al. Marital status, health and mortality. Maturitas 2012;73:295-9.

31 Pompili M, Vichi M, Qin P, et al. Does the level of education influence completed suicide? A nationwide register study. J Affect Disord 2013;147:437-40.

32 Lunner Kolstrup C, Kallioniemi M, Lundqvist P, et al. International perspectives on psychosocial working conditions, mental health, and stress of dairy farm operators. J Agromedicine 2013;18:244-55.
33 Kunde L, Kõlves K, Kelly B, et al. Pathways to suicide in Australian farmers: a life chart analysis. Int J Environ Res Public Health 2017;14:352.

34 Fraser $C E$, Smith $\mathrm{KB}$, Judd F, et al. Farming and mental health problems and mental illness. Int J Soc Psychiatry 2005;51:340-9.

35 Perceval M, Kõlves K, Reddy P, et al. Farmer suicides: a qualitative study from Australia. Occup Med 2017;67:383-8.

36 Qin P. Suicide risk in relation to level of urbanicity--a population-based linkage study. Int J Epidemio/ 2005:34:846-52.

37 von Borczyskowski A, Lindblad F, Vinnerljung B, et al. Gender differences in risk factors for suicide: findings from a Swedish national cohort study. Can J Psychiatry 2010;55:108-11.

38 European Commission. Firearms in the European Union. Flash Eurobarom, 383, 2013. Available: https://ec.europa.eu/commfrontoffice/publicopinion/flash/fl_383_en.pdf

39 WHO Statistical Information System. WHO mortality database, 2014. Available: http:// www.who.int/healthinfo/statistics/mortality_rawdata/en/index.html [Accessed $11 \mathrm{Apr}$ 2018].

40 Saunderson T, Haynes R, Langford IH. Urban-Rural variations in suicides and undetermined deaths in England and Wales. J Public Health 1998;20:261-7. 